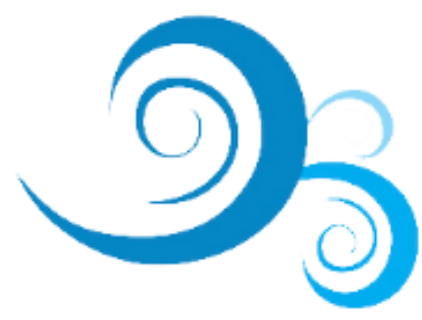

\title{
OS GRANDES PROJETOS HIDRELÉTRICOS NA AMAZÔNIA: DA DESPOLITIZAÇÃO À REPOLITIZAÇÃO E CONTESTAÇÃO DE CONHECIMENTOS
}

\author{
FERNANDA MELLO SANT'ANNA \\ Professora Assistente do Departamento de Relações Internacionais da Universidade \\ Estadual Paulista "Júlio de Mesquita Filho" (UNESP), Franca (SP), Brasil \\ ORCID: https://orcid.org/0000-0003-1163-0588 \\ fernanda.mello@unesp.br \\ RAÍ LUÍS HONORATO \\ Mestrando pelo Programa de Pós-Graduação em Relações Internacionais San \\ Tiago Dantas (UNESP, UNICAMP, PUC-SP), São Paulo (SP), Brasil \\ ORCID: https://orcid.org/0000-0001-6351-2116 \\ rai-honorato@hotmail.com

\begin{abstract}
PEDRO HENRIQUE BORTOLETTO
Graduando em Relações Internacionais pela Universidade Estadual Paulista "Júlio de Mesquita Filho" (UNESP), Franca (SP), Brasil ORCID: https://orcid.org/0000-0002-6612-5450
\end{abstract}

casalecchipedro@hotmail.com

\begin{abstract}
Resumo: Este artigo tem como objetivo discutir a construção de grandes projetos hidrelétricos na Amazônia brasileira, a partir das estratégias de despolitização utilizadas para o seu tratamento técnicocientífico e o processo de contestação de conhecimentos com base na mobilização social contrária a esses projetos. A hidreletricidade tem sido vista nos últimos anos como uma alternativa limpa e renovável de fornecimento de energia frente às mudanças climáticas, justificando a sua retomada na Bacia Amazônica e omitindo seus impactos socioambientais. As estratégias de despolitização visam mobilizar conhecimentos para que as infraestruturas hidroelétricas sejam compreendidas a partir de uma abordagem técnica, que compactua com a ideia de projetos infalíveis da engenharia moderna que ignora riscos associados à sua construção e operação. Estes projetos afetam de modo desigual os grupos sociais, sendo os mais impactados aqueles que são forçados a se deslocarem e tem seus modos de vida alterados. Assim, são analisadas as estratégias de despolitização empregadas para a construção das usinas de Santo Antônio, Jirau e Belo Monte, bem como a mobilização social contrária aos projetos como meio de repolitização da temática das grandes hidrelétricas, demonstrando a contestação de conhecimentos nesta arena.
\end{abstract}

Palavras-chave: Bacia Amazônica Brasileira; Despolitização; Hidroeletricidade.

\section{LARGE HYDROELECTRIC PROJECTS IN THE AMAZON: FROM DEPOLITICIZATION TO REPOLITICIZATION AND CONTESTATION OF KNOWLEDGE}




\begin{abstract}
This article aims to discuss the construction of large hydroelectric projects in the Brazilian Amazon, based on the depoliticization strategies used for their technical-scientific treatment and the process of contesting knowledge based on the social mobilization contrary to these projects. Hydroelectricity has been seen in recent years as a clean and renewable alternative for energy supply in the face of climate change, justifying its resumption in the Amazon Basin and omitting its social and environmental impacts. Depoliticization strategies aim to mobilize knowledge so that hydroelectric infrastructures are understood from a technical approach, which agrees with the idea of infallible projects of modern engineering that ignores risks associated with their construction and operation. These projects affect social groups unequally, the most impacted are those who are forced to move and have their ways of life altered. Thus, the depoliticization strategies employed for the construction of the Santo Antônio, Jirau and Belo Monte plants are analyzed, as well as the social mobilization contrary to the projects as a means of repoliticizing the issue of large hydroelectric plants, demonstrating the contestation of knowledge in this arena.
\end{abstract}

Key-words: Brazilian Amazon Basin; Depoliticization; Hydroelectricity.

\title{
LOS GRANDES PROYECTOS HIDROELÉCTRICOS EN LA AMAZONÍA: DE LA DESPOLITIZACIÓN A LA REPOLITIZACIÓN Y LA REFUTACIÓN DE CONOCIMIENTOS.
}

\begin{abstract}
RESUMEN: Este artículo tiene como objetivo discutir la construcción de grandes proyectos hidroeléctricos en la Amazonía brasileña, a partir de las estrategias de despolitización utilizadas para su tratamiento técnico-científico y el proceso de impugnación del conocimiento basado en la movilización social contraria a estos proyectos. La hidroelectricidad ha sido vista en los últimos años como una alternativa limpia y renovable para el suministro de energía ante el cambio climático, justificando su reanudación en la cuenca amazónica y omitiendo sus impactos sociales y ambientales. Las estrategias de despolitización tienen como objetivo movilizar el conocimiento para que las infraestructuras hidroeléctricas se entiendan desde un enfoque técnico, que concuerda con la idea de proyectos infalibles de ingeniería moderna que ignoran los riesgos asociados a su construcción y operación. Estos proyectos afectan de manera desigual a los grupos sociales, los más impactados son los que se ven obligados a desplazarse y tienen alterados sus modos de vida. Así, se analizan las estrategias de despolitización empleadas para la construcción de las centrales Santo Antônio, Jirau y Belo Monte, así como la movilización social contraria a los proyectos como forma de repolitizar el tema de las grandes hidroeléctricas, demostrando el desafío del conocimiento en esta arena.
\end{abstract}

PALABRAS CLAVE: Cuenca Amazónica Brasileña; Despolitización; Hidroelectricidad.

\section{INTRODUÇÃO}

A Bacia Amazônica, maior bacia hidrográfica do mundo, tem apresentado nas últimas décadas diversas transformações espaciais. Entre os grandes projetos implementados nesta região estão as grandes hidrelétricas e suas inter-relações com os processos globais em curso, tanto em relação às frentes de expansão da exploração capitalista dos recursos naturais como também a política ambiental global, neste caso específico vinculado à mitigação das mudanças climáticas. Os países que a compartilham têm buscado explorar o grande potencial de energia hidrelétrica 
existente, em especial o Brasil, que possui a maior parcela da Bacia em comparação com os demais países.

Este artigo busca analisar o processo de construção de grandes hidrelétricas na Bacia Amazônica brasileira que gera diversos conflitos socioambientais e contestação de conhecimentos a partir da utilização de estratégias de despolitização e repolitização da temática por diferentes grupos sociais. A defesa dos projetos hidrelétricos se baseia no paradigma da modernização hidráulica e desconsidera os riscos desiguais destas infraestruturas. Para tanto, foi realizada uma revisão bibliográfica e documental, que permitiram construir um quadro teórico conceitual sobre as estratégias de despolitização e repolitização empregadas por diferentes grupos sociais, bem como a produção desigual de riscos.

Na primeira parte é apresentado o contexto atual das grandes hidrelétricas no mundo e o papel de organizações internacionais como o Banco Mundial e a Comissão Mundial sobre Barragens nesta temática. A segunda parte inicia a discussão sobre a despolitização como estratégia utilizada nos grandes projetos de hidrelétricas. Em seguida se analisa como o conhecimento é mobilizado por essas estratégias e para a produção da ignorância em relação aos riscos desiguais gerados pelas grandes hidrelétricas. Nas duas últimas partes do artigo são apresentados os casos específicos das grandes hidrelétricas de Santo Antônio, Jirau e Belo Monte na Amazônia brasileira, bem como se analisa as estratégias de despolitização e repolitização empregadas por diferentes grupos a favor e contra a construção destas.

\section{As grandes hidrelétricas no mundo: riscos, mudanças climáticas e investimentos}

Os processos de construção de grandes hidrelétricas (e outras grandes barragens) no mundo apresentam similaridades, pois estão relacionados ao modo capitalista moderno de exploração dos recursos naturais que tem por fundamento a epistemologia moderna baseada no binômio sociedade-natureza. Durante o século XX foram construídas milhares de barragens e usinas hidrelétricas em todo mundo (CDM, 2000), baseada num modelo de modernização hidráulica em que a água passou a ser vista primordialmente como insumo básico para a produção econômica de acumulação do capital (GOLDMAN, 2007; BOELENS, et al., 2015). 
Todavia, este também foi um período de grande mobilização social, e nas décadas de 1980 e 1990 movimentos sociais e Organizações Não-Governamentais (ONGs) estabeleceram redes transnacionais de mobilização contra a construção de grandes barragens, influenciando até mesmo as ações dos grandes financiadores internacionais como o Banco Mundial (BM). Neste período, a opinião pública começou a ser afetada pelas mobilizações sociais que adotaram as novas tecnologias da informação para a formação de redes transnacionais. Como exemplo, vale citar a mobilização em oposição ao controverso projeto da barragem Sadar Soravar, no vale Narmada na Índia, em 1993, que forçou o BM a abandonar o projeto e a cancelar diversos outros com o mesmo objetivo pelo mundo (BOSSHARD, 2010).

Em Curitiba no ano de 1997 ocorreu a primeira reunião internacional das pessoas afetadas por barragens. Nesta reunião, os participantes demandaram a criação de uma comissão internacional independente, para conduzir uma ampla avaliação e revisão sobre as grandes barragens. Ao final, o próprio BM apoiou a ideia, ainda que possa ter sido uma estratégia para desviar o foco do seu papel na construção dessas barragens (BOSSHARD, 2010).

Uma das deliberações do encontro foi a concepção da Comissão Mundial de Barragens (CMB). Para Bosshard (2010), a sociedade civil pretendia com a CMB fazer uma ampla avaliação dos projetos de desenvolvimento e sua efetividade. Por outro lado, a indústria de barragens (chamada em inglês de Dam Industry ${ }^{1}$ ) estava mais interessada na formulação de um conjunto de padrões para a construção de barragens. A sociedade civil teve participação proativa durante todo o trabalho da $\mathrm{CMB}$, ao passo que os representantes do setor de barragens participaram com menos intensidade.

Em novembro de 2000, a Comissão Mundial de Barragens (2000) publica seu primeiro relatório indicando que a efetivação dos mega projetos hidráulicos contribuiu com o aumento de até $28 \%$ do potencial aquecimento do planeta a partir da emissão de Gases de Efeito Estufa (GEE). Ainda é apontado que em determinados contextos,

\footnotetext{
${ }^{1}$ De acordo com Bosshard (2010) a indústria internacional de barragens é um grupo heterogêneo formado por formuladores de projetos, empresas de serviços públicos, empreiteiros, empresas de construção, fornecedores de equipamentos e empresas de engenharia, incluindo empresas que desempenham várias dessas funções. Este grupo deu origem a uma organização internacional, a Associação Internacional de Hidreletricidade (em inglês: International Hydropower Association - IHA), o principal grupo do setor.
} 
a emissão bruta desses gases foi maior do que a produzida por fontes de energia termal. Isso também contribuiu para o afastamento do BM dos mega projetos hidrelétricos.

Mais à frente, na segunda década do século XXI, é possível observar a retomada dos investimentos internacionais em projetos de grandes hidrelétricas em todo mundo. O BM reassume o financiamento destes projetos, tendo como uma das justificativas a ideia de que a hidroeletricidade seria uma fonte de energia "limpa" e renovável necessária para os esforços de mitigação das mudanças climáticas (ZARFL et al., 2015; HERNANDEZ F. D., 2012).

Um dos elementos que fomentaram esse discurso foi a promoção das metas e compromissos estabelecidos durante as reuniões da Convenção Quadro das Nações Unidas para as Mudanças do Clima, requerendo que os países atinjam suas demandas crescentes de energia por meio do uso de recursos energéticos que estejam em consonância com o ideal de sustentabilidade acordados na conferência. A justificativa das mudanças climáticas é, deste modo, um dos maiores impulsionadores de investimentos em hidreletricidade.

Entretanto, esse impulso que o combate às mudanças climáticas e a criação do mercado de carbono deram aos novos projetos de hidrelétricas já é contestado por pesquisas científicas:

Infelizmente, o fato que as barragens na Amazônia produzem grandes quantidades de gases de efeito estufa, especialmente durante os primeiros dez anos de operação (o horizonte de tempo para o atual projeto de MDL), tem sido demonstrado em diversos estudos na literatura científica (e.g., GalyLacaux et al., 1997, 1999; Fearnside, 2002a, 2004, 2005a,b, 2006a, 2008, 2009; Delmas et al., 2004; Abril et al., 2005; Guérin et al., 2006, 2008; Kemenes et al., 2008, 2011; Gunkel, 2009; Pueyo \& Fearnside, 2011). Enquanto ressalvas e suposições são detalhadas em todos esses estudos, a conclusão geral de que represas tropicais emitem quantidades significativas de gases de efeito estufa em seus primeiros dez anos é clara e robusta (FEARNSIDE, 2015b, p. 101).

Sendo assim, representar a construção de usinas hidrelétricas como energia limpa é confundir o "recurso com o instrumento", já que a água é renovável, mas as barragens não são. Ou seja, ainda que o ciclo da água seja considerado como renovável, "não podemos dizer o mesmo da conversão de energia hidrelétrica, pois esta necessita da dinâmica de um rio, que já teve sua dinâmica original alterada, e da persistência operacional de um conjunto de máquinas" (HERNANDEZ, 2012, p. 793). Isto não é levado em conta em afirmações que defendem que as hidrelétricas podem 
mitigar as mudanças climáticas. Desse modo, a construção e operação de usinas hidrelétricas não são necessariamente estratégias de mitigação, mas, na verdade, caminho pelo qual se é possível alcançar objetivos de crescimento econômico (AHLERS, et al. 2015).

Para além dos efeitos concernentes às mudanças do clima, há também os problemas causados às populações que residem próximas aos locais de construção das barragens que, em geral, são minimizados pelo argumento de que os benefícios (aumento da oferta de energia) serão muito maiores do que os riscos e impactos associados. Esta simplificação esconde, propositalmente, a produção desigual dos riscos e quais serão os reais beneficiados, pois não existem garantias suficientes de que o aumento dos investimentos e projetos no setor hidrelétrico no Brasil contribua na prática para diminuir o número de pessoas sem acesso à energia elétrica. Afinal, esta expansão da hidroeletricidade pode estar direcionada por interesses econômicos privados para exportação ou para o desenvolvimento do setor industrial. Como também pode ser o caso de outros países que estão aumentando a sua produção hidrelétrica, como o Quênia, Tanzânia, Paquistão e Nigéria (ZARFL, et al. 2015, p. 167).

Na América do Sul, Zarfl et al. (2015) afirmam que as bacias Amazônica e do Prata no Brasil concentrarão a maior parte das novas hidrelétricas. Assim como, a bacia do Ganges-Brahmaputra na Índia e Nepal e a bacia do Yangtzé na China terão a maior parte das construções de barragens na Ásia. Projetos de grandes hidrelétricas são esperados e muitos já se encontram implantados na Ásia, América do Sul e África.

Todavia, este aumento na construção de hidrelétricas representará apenas uma pequena fração de crescimento da produção total de eletricidade devido ao grande aumento da demanda global projetada para 2040. Esta retomada da aceleração na construção de barragens hidrelétricas levará a fragmentação de 25 das 120 grandes bacias hidrográficas atualmente classificadas como de fluxo livre (sem barragens), principalmente na América do Sul. Em todo o mundo o número de rios com fluxo livre diminuirá aproximadamente $21 \%$. Além do que, a construção das barragens planejadas irá afetar as regiões mais sensíveis ecologicamente no mundo, como as bacias Amazônica, do Mekong e do Congo, que juntas possuem 18\% da biodiversidade de peixes de água doce do mundo (ZARFL, et al., 2015). 
O potencial tecnicamente aproveitável do sistema hidráulico global corresponde a um total de 15.899 TWh/ano do valor teórico de 40.700 TWh/ano. Aproximadamente $65 \%$ desse recurso em uso potencial está concentrado num total de 10 países. O Brasil ocupa a terceira posição de destaque, ficando atrás apenas dos Estados Unidos e China (BRASIL, 2007). No caso do Brasil, em específico, atualmente a Oferta Interna de Energia (OIE) fornecida pelas hidrelétricas instaladas tem decrescido devido a fatores climáticos adversos e ao planejamento estratégico de diversificação das fontes de geração elétrica, apesar da construção de novas hidrelétricas e o aumento da capacidade instalada.

Nesse sentido, um amplo conjunto de empreendimentos são planejados na expansão hidrelétrica para a região Norte do Brasil através de estudos que inventariam as bacias dos rios Aripuanã, Trombetas, Juruena, Araguaia, Sucunduri, Branco, Itacaiunas, Jarí, Jatapu e Tapajós, em um total de 32.950 MW (BRASIL, 2008). Esta é a região onde ocorrerá a maior expansão hidrelétrica, em virtude da entrada operacional até 2021 de grandes projetos estratégicos, com destaque a Belo Monte, Sinop, Cachoeira Caldeirão, São Manoel, São Luiz do Tapajós, Jatobá, São Simão Alto, Marabá e Salto Augusto Baixo. Dessa maneira, os projetos hidrelétricos elevarão a participação da região Norte de 10\%, no início de 2012, para 24\% da capacidade instalada no Sistema Interligado Nacional (SIN), em 2021, totalizando 32.783 MW de expansão (BRASIL, 2012).

Esta expansão buscando atender uma demanda crescente de energia esconde o fato de que o aumento da oferta de hidroeletricidade gera a distribuição desigual de riscos e custos para a parcela da população que vive próxima às barragens e depende dos recursos da região, além das grandes perdas em termos de biodiversidade. Por que os impactos ecológicos e sociais das grandes barragens hidrelétricas não são comuns nos discursos que a promovem? Por que os desastres relacionados às grandes barragens que já ocorreram em todo o mundo recebem pouca atenção nos debates sobre barragens? Estas questões suscitam uma análise sobre um processo discursivo em que as grandes barragens hidrelétricas são representadas como grandes obras da engenharia humana, infalíveis e seguras e que, portanto, seus desastres relacionados estariam fora do controle humano. 

hidrelétricas

A crença de que a tecnologia e a engenharia irão resolver todos os problemas humanos, entre eles os socioambientais, está por trás do tratamento técnico dado a essas questões. Desta forma, os problemas socioambientais são apresentados como problemas técnicos que serão resolvidos a partir da tecnologia. Por outro lado, é o próprio avanço tecno-científico moderno que gerou a sociedade de risco em vigor, como é o caso das barragens (BECK, 2011). De acordo com Huber et al. (2016), os riscos associados às grandes estruturas hidráulicas são frequentemente tratados a partir da moralização tecnológica, despolitizados, removidos da esfera do debate público e, até mesmo, são empregadas tentativas de remoção das controvérsias em torno dos desastres da memória coletiva organizada.

Comumente entende-se por risco a combinação da probabilidade de ocorrer fenômenos biofísicos ou tecnológicos, a exposição aos riscos produzidos por esses fenômenos e a capacidade de adaptação da sociedade diante desses eventos. A problemática apontada nessa concepção, entretanto, é que ela direciona a culpa pelos desastres em barragens às calamidades naturais e deixa de lado as dinâmicas sociais, institucionais e políticas que envolvem as decisões tomadas e que efetivamente produzem risco sem considerar os diferentes níveis de vulnerabilidade social (HUBER, 2019a).

Essa noção se instala e ganha espaço no imaginário sociopolítico pela alta confiança atribuída aos grandes projetos de engenharia responsáveis por dar materialidade às barragens. A autora aponta que isso toma forma a partir da aplicação do que ela chama de lacunas de conhecimento. Por exemplo, ainda que existam incertezas inevitáveis às estruturas tecnológicas associadas às barragens, as formulações e concepções sobre as inseguranças inerentes a esses sistemas são ignoradas e negligenciadas, exaltando a alta capacidade das tecnologias atuais de sustentação dessas estruturas e negando o histórico de falhas nos sistemas de barragens (HUBER, 2019a).

No final dos anos 2000 esse panorama sofreu algumas mudanças, principalmente por conta da má fama adquiridas pelas barragens, em consequência das mobilizações sociais e da publicação do Relatório da CMB. Em resposta a esse 
contexto, a solução para a manutenção das hidrelétricas foi encontrada na privatização das indústrias desse setor. Em vista disso, o governo brasileiro até 2002, por exemplo, desregulou cerca de 170 empreendimentos estatais, dentre eles o mercado de energia elétrica, com o objetivo de minimizar a intervenção estatal e atrair investimentos estrangeiros (BANDEIRA, 2005; MOTTA, 2001). Como consequência desses movimentos, Huber (2019a) argumenta que tais iniciativas foram responsáveis por produzir uma indústria pouco transparente e que constrói barragens sem levar em conta a distribuição desigual dos riscos, incluindo os efeitos relativos às mudanças do clima sobre a infraestrutura das hidrelétricas. Ignorar este problema seria parte de uma estratégia econômica por parte dos investidores desses projetos, que tem por objetivo salvaguardar a viabilidade financeira das barragens e mantê-las pouco custosas (HUBER, 2019a; VALÊNCIO, 2017).

Boelens, Shah e Bruins (2019) apontam que a da produção da ignorância sobre os riscos, ou seja, a estratégia de ignorar os riscos socioambientais e tecnológicos, é empregada pois os grandes projetos de hidrelétricas possuem incertezas e imprevisibilidades. Saber ou prever todos os cenários negativos iriam impedir a execução de projetos de grande escala ou até mesmo do "progresso" e "desenvolvimento". Existe, portanto, uma conexão entre ignorância produzida e o risco produzido.

Para além disso, muitos estudos têm demonstrado a vinculação de grandes obras hidráulicas com os discursos de desenvolvimento nacional e interesse nacional, que resultaram em ações autoritárias (ATKINS, 2019; BERMANN, 2012; HERNANDEZ, 2012; MOHAMUD, 2016), e se utilizaram de estratégias de despolitização para que os projetos fossem construídos sem o devido debate público e ignorando as contestações. Estas evidências em diferentes contextos e lugares do mundo levantam questões sobre a real existência de participação social e o cumprimento de todo processo democrático, considerando que a democracia representativa não iria ruir por meio de golpes como no passado, mas a partir de dentro de suas próprias instituições (CASTELLS, 2018).

Outrossim, a utilização de representações quantitativas e baseadas somente em justificativas técnico-científicas sobre o que é o risco tem um efeito de despolitização da governança ambiental, comprometendo a participação pública nesse contexto e tornando pouco democrático o processo de tomada de decisões. 
Nesse sentido, a construção de argumentos a partir dessa lógica e apresentando-os como tecnicamente complexos, ainda que essencialmente sejam fundamentados em escolhas políticas e ideológicas, desqualifica a opinião de membros externos à comunidade científica e coloca a discussão sobre a ideia de risco como competência exclusiva de especialistas (HUBER, 2019a). O que se entende então como despolitização? E qual a sua relação com os riscos e os desastres relacionados aos grandes projetos de hidrelétricas?

A despolitização funciona por meio da mudança de arena, na realocação de questões, pessoas e instituições da área política de debate e deliberação para arenas governadas supostamente por órgãos de especialistas técnicos. A justificativa apresentada por quem defende essa mudança é que os órgãos de especialistas seriam guiados por regras e regulamentações neutras, apolíticas e por "fatos" científicos não negociáveis, sem ambiguidade e incertezas, ao contrário da arena política guiada por valores sociais contestáveis. Portanto, está baseada na crença da neutralidade científica e de uma verdade incontestável (BOELENS, et al., 2019). A ignorância também é frequentemente intencional e estrategicamente promovida como estratégia de despolitização e mantida para controlar as informações que chegam na arena pública, contribuindo para a despolitização de certas questões. Trata-se de estratégias de mobilização do conhecimento e da ignorância (HUBER et al., 2016).

Tendo isso em mente, diversos autores tem debatido sobre a política "despolitizada", que é caracterizada pelo declínio no engajamento popular na política e a emergência de formas tecnocráticas pós-democráticas de governança, pela erosão da democracia e da esfera pública, também chamada de uma era pósideológica (BECK, 2011; WOOD e FLINDERS, 2014; MOUFFE, 2005; HAY, 2007; JENKINS, 2011).

A pós-política seria a crença de que as lutas políticas conduzidas por ideologias são contra produtivas para a governança. Existe, portanto, uma repressão do "político" como lugar de disputa sobre objetivos, prioridades e valores a serem seguidos. Este é colonizado pelo modelo da "boa governança" pós-democrática, técnicoadministrativa, vista como consensual baseada num acordo sobre os problemas a serem enfrentados e suas soluções. As diferentes opiniões só são permitidas neste acordo da governança se não questionarem o estado atual da configuração econômico-política neoliberal (MOUFFE, 2005). 
Aqueles que discordam são colocados de fora do consenso e radicalmente excluídos e, se necessário, tratados como extremistas e terroristas, como tem sido chamados os ambientalistas no atual governo do presidente Bolsonaro no Brasil (OBSERVATÓRIO DO CLIMA, 2019). Mas esta visão sobre aqueles que discordavam também pode ser observada em governos precedentes no Brasil, que construíram um discurso único que representava aqueles que se posicionavam contrários às grandes barragens na Amazônia como contrários ao desenvolvimento do país (LAYRARGUES, 2018).

A despolitização de arranjos e discursos de governança disfarçam a natureza política, contenciosa e normativa do conteúdo de políticas, projetos e intervenções ambientais com o objetivo último de ignorar a contestação na política democrática, sendo esta última frequentemente considerada um obstáculo para a ação imediata. No caso das mudanças climáticas, por exemplo, apelos públicos explícitos tem sido articulados para a sua despolitização por políticos e experts como Tony Blair e Anthony Giddens, com a justificativa de que combater a crise ambiental global é tão urgente que estas questões devem ser retiradas da esfera demorada da política partidária e enfrentada pelo consenso e cooperação em torno de soluções administrativas e tecnocráticas (SWYNGEDOUW, 2009; HUBER, 2019b).

Wood e Flinders (2014), apoiados no estudo de Hay (2007), apontam que a despolitização pode se dar por estratégias governamentais, sociais e discursivas, sendo que existe uma interdependência e interação entre essas três faces da despolitização. A estratégia governamental de despolitização tem sido a mais discutida na literatura e se baseia na delegação de poderes pelos políticos, partindo de uma visão estadocêntrica da política e do político. Já a despolitização social se refere ao processo de deliberação política e ocorre quando existe um esvaziamento do debate público sobre uma temática, com a possibilidade de estar relacionado ao desengajamento político e declínio da participação social nas instâncias democráticas. Assim, o foco não está apenas nos líderes políticos dos governos mas também em outros atores sociais, suas capacidades e papéis, tais como a mídia, movimentos sociais, grupos religiosos, associações empresariais, entre outros, que promovem a apatia política e negam a existência de escolhas políticas em relação a certos temas.

Finalmente, os autores apresentam a despolitização discursiva como fruto de uma perspectiva mais descentralizada que reconhece que atos de discurso podem 
formar necessidades, permanências, imobilidade, fechamento e fatalismo, conciliando, negando ou removendo a contingência, atuando como ferramenta poderosa de despolitização (WOOD e FLINDERS, 2014; JENKINS, 2011). Desta forma, a despolitização ocorre quando o debate sobre um tema se torna tecnocrático, administrativo ou enviesado para um certo objetivo e, consequentemente, alterando seu conteúdo. A promoção de um assunto a partir de uma única interpretação e a negação de outras escolhas gera vias para a despolitização. Por outro lado, a dinâmica de politização discursiva seria a promoção de um tópico a nível público, onde interpretações concorrentes existem como escolhas possíveis:

'Politicisation', in this sense, is a radical act of recognising 'the political', the possibility that society can be constituted differently, it is the opposite of fatalism and denial. Discursive perspectives on depoliticisation therefore reasonate with Bauman's In search of politics (1999), in the sense that they are concerned with how language and a careful approach to the 'framing' of issues can serve to close down certain options by making any opposition appear almost 'irrational' (WOOD e FLINDERS, 2014, p. 162)

Neste sentido, essas estratégias de despolitização se efetivam quando o Estado e outros grupos sociais mobilizam o conhecimento e a produção de ignorância despolitizando uma temática, como é o caso das hidrelétricas.

\section{A mobilização do conhecimento e da ignorância para despolitizar as grandes hidrelétricas}

No setor hídrico, a epistemologia dos projetos de grandes barragens é dominada pelo conhecimento moderno positivista produtor de uma ordem hidrossocial particular. Esta ordem emergiu com a construção do Estado moderno a partir do controle e colonização da natureza e seus rios. A canalização e transformação do rio em uma linha reta "racional" é considerada sinônimo de desenvolvimento e modernização. À vista disso, este conhecimento de base técnico-cientifica pretensiosamente despolitizado é usado pelo Estado para justificar projetos de modernização hidráulica como as grandes barragens hidrelétricas (BOELENS, et al., 2019; SWYNGEDOUW, 2015).

A modernização hidráulica é um projeto inerentemente socioterritorial, baseado em um modelo moderno de gestão "racional" da água que pretende fazer desaparecer as diferenças sociais e culturais, que entende a modernização como padronização. 
Deste modo, a despolitização do conhecimento moderno sobre a água está relacionada ao regime de verdade construído sobre a gestão racional dos recursos hídricos a partir de uma epistemologia universalista que separa os conhecimentos legítimos daqueles considerados ilegítimos. Os outros conhecimentos não modernos sobre a água são desvalorizados e considerados inferiores e não-científicos, nãoracionais. Contudo, a esfera do conhecimento envolve múltiplas realidades sociais, desigualdades de poder e diferentes modos de construir e organizar o mundo e não uma simples acumulação de fatos. Faz parte da construção do conhecimento a interação entre elementos sociais, cognitivos, culturais, institucionais e situacionais. Por isso, o conhecimento é sempre provisório, parcial e contextual, e o poder é sempre relacional, a partir da interação entre sujeitos (BOELENS, et al., 2019; FOUCAULT, 1979).

Para Boelens, Shah e Bruins (2019) o planejamento e construção de mega sistemas hidro-tecnológicos, como as usinas hidrelétricas, geram conflitos entre grupos sociais e disputas entre diferentes regimes de conhecimento. Geralmente, estes conflitos e a contestação de conhecimentos tem se dado entre grupos de usuários e comunidades afetadas por barragens versus engenheiros ou burocratas, sobre o desenho da barragem, localização, alocação e distribuição de água e eletricidade.

Nestes conflitos também é perceptível, para Martinez-Alier (2007) a existência de diversos discursos de valoração sobre os recursos naturais e serviços ecológicos e alerta para a incomensurabilidade de valores. Isto é, não existe uma metodologia em que seja possível medir os valores a partir de um valor universal, uma vez que ele não existe, mas sim diferentes valores ligados aos seus contextos históricos culturais específicos.

Por outro lado, a comensurabilidade é utilizada para padronizar racionalidades de governança da água totalmente diferentes e também territórios hidrossociais em uma única métrica comum, a partir da objetificação e quantificação da água, ignorando os valores e significados sociais (despersonalizando) e, portanto, transformando a água em commodity, assim como o próprio território e os recursos naturais. Trata-se da utilização de uma métrica equalizadora que transforma uma "cultura particular" (Ocidental moderna) em universal, que é o modo como os especialistas transformam 
as normas, valores e definições relacionados a gestão dos recursos hídricos nesta métrica universal (BOELENS, et al., 2019).

A produção do conhecimento sobre as grandes hidrelétricas, e barragens de forma geral, é uma arena, ou até mesmo um campo de batalha, no qual valores, entendimentos e interesses de diferentes atores são postos em confronto. Na democracia é perceptível a contestação e encontro de conhecimentos. No entanto, tem sido observado a parcialidade nas instituições no caso dos grandes projetos hidrelétricos que são dominados pelo conhecimento de especialistas e interesses financeiros. As decisões que podem afetar muitas pessoas, são debatidas e decididas fora das instituições políticas relacionadas ao Estado e a democracia. Em decorrência disso, "o potencial de configuração da sociedade migra do sistema político para o sistema sub-político da modernização científico-técnica-econômica" (BECK, 2011, p. 279). A política é dispersada e deslocada para as empresas, bancos, laboratórios, entre outros espaços privados (BOELENS, et al., 2019).

Nesse sentido, Martins e Lima (2017), ao realizarem uma análise sobre a formação acadêmica/profissional dos participantes de um Comitê de Bacia Hidrográfica $(\mathrm{CBH})$ do estado de São Paulo, concluíram que existe uma predominância da participação de pessoas da área da engenharia. A predominância de um saber técnico da engenharia na gestão das águas ocorre também em outros $\mathrm{CBHs}$ e revela uma luta cognitiva no interior destes espaços de gestão dos recursos hídricos e um exemplo de sua tecnificação:

\begin{abstract}
Considerando o comitê de bacia como um espaço social onde há inevitavelmente lutas constantes pela imposição de princípios de visão e divisão do mundo social, pode-se encontrar relações de poder e dominação exercidas por um grupo de agentes sobre os demais. Este poder simbólico é legitimado pela quantidade de capital específico que atua neste espaço - no caso, o conhecimento técnico e científico que é expresso através do habitus linguístico. $O$ que se sugere em relação à interpretação destas arenas de gestão ambiental é que, para que se possa ultrapassar os aspectos puramente técnicos da governança, é essencial introduzir o conceito de poder para compreender que não se está apenas diante de um novo modo de organizar as práticas gestoras, mas sim de uma modalidade específica de ordenar a realidade social e suas relações no que tangem ao uso e acesso aos recursos naturais (MARTINS e LIMA, 2017, p. 145).
\end{abstract}

As estratégias de despolitização e produção da ignorância serão analisadas nos casos de três hidrelétricas construídas na porção brasileira da Bacia Amazônica, sendo elas as Usinas Hidrelétricas (UHE) de Santo Antônio (RO), Jirau (RO) e Belo Monte (PA). 


\section{Grandes hidrelétricas na Amazônia brasileira: Santo Antônio, Jirau e Belo Monte}

Para Bertha Becker (2007), durante grande parte do século XX, o Estado foi o grande planejador da exploração da Amazônia por meio de um projeto geopolítico de modernização desta parte do território nacional. Ainda assim, é possível afirmar que os demais países amazônicos também apresentaram algumas semelhanças no modelo de exploração e ocupação de seus respectivos territórios amazônicos (SANT'ANNA, 2017). Becker (2007) afirma que, no contexto da globalização, alterouse o significado da Amazônia como fronteira do uso científico-tecnológico da natureza, associado a uma nova geopolítica mundial não mais apoiada na apropriação direta dos territórios, mas influenciando a decisão sobre o uso dos seus recursos naturais. Deste modo, a fronteira hidrelétrica avança na Bacia Amazônica relacionado aos processos globais em curso (HERNANDEZ, 2012).

Após os anos 2000 percebe-se uma retomada do debate sobre os projetos de grandes hidrelétricas no Brasil. Nota-se que grande parte desses projetos estão localizados na Bacia Amazônica, onde já existiam experiências desastrosas e com referências negativas sobre os seus impactos, como no caso das hidrelétricas de Balbina (AM) e Tucuruí (PA) (FEARNSIDE, 2015a; BERMANN et al., 2010). O resgate de antigos projetos concernentes à infraestrutura do país sugere o intuito de estimular o desenvolvimento econômico, remontando a figura do Estado como o grande impulsor do desenvolvimento nacional, estratégia essa que já foi adotada no governo Vargas e durante a ditadura militar (PEREIRA, 2013).

Grande parte das hidrelétricas construídas e em construção atualmente na Amazônia brasileira estavam presentes no Plano Nacional de Energia Elétrica 1987/2010 (Plano 2010), apresentado pelo Ministério das Minas e Energia e pela Eletrobrás em dezembro de 1987. Neste Plano constava o planejamento de 79 barragens, e algumas delas estavam atreladas à construção das principais rodovias de acesso à região amazônica, como a BR-364, a BR-163 e a Rodovia Belém-Brasília. Contudo, a execução desses projetos foi adiada por diversas vezes, ocorrendo, por sua vez, o resgate dessas obras no Programa de Aceleração do Crescimento (PAC) 
durante o governo de Luís Inácio Lula da Silva, praticamente 30 anos depois (FEARNSIDE, 2015b; BORGES, 2017).

Nos últimos anos, três dessas grandes hidrelétricas geraram grande politização, mobilização social e contestação de conhecimentos. Duas delas fazem parte do chamado "Complexo do Madeira", sendo elas Santo Antônio e Jirau na bacia do rio Madeira, na região que abrange parte do município de Porto Velho no estado de Rondônia. Estas duas hidrelétricas previstas no PAC também faziam parte dos projetos da Iniciativa para a Integração da Infraestrutura Regional Sul-Americana (IIRSA $^{2}$ ) do Eixo Peru-Brasil-Bolívia, do grupo de projetos do Corredor Fluvial MadeiraMadre de Dios-Beni, que previa também a construção da usina hidrelétrica binacional de Guajará-Mirim, na fronteira entre Bolívia e Brasil, e a usina boliviana de Cachuela Esperanza (SANT'ANNA, 2012).

A hidrelétrica de Santo Antônio está a aproximadamente $7 \mathrm{~km}$ do centro de Porto Velho (RO), cujo local é denominado de cachoeira de Santo Antônio, sob a responsabilidade dos consórcios Santo Antônio Energia SA. O investimento inicial da usina foi de aproximadamente 20 bilhões de reais, a partir de recursos federais, empresariais e de bancos públicos e privados e com capacidade inicialmente prevista de $3.150 \mathrm{MW}$, que foi ampliada posteriormente para uma potência de 3.568 MW. Sua construção começou em 2008 e as suas duas primeiras turbinas entraram em funcionamento comercial em 2012 (BORGES, 2017).

Já a usina de Jirau, também instalada no rio Madeira e no município de Porto Velho, localiza-se próxima aos distritos de Jacy-Paraná e Mutum-Paraná, na área da cachoeira do Padre. Incialmente prevista como uma capacidade de $3300 \mathrm{MW}$ acabou sendo alterada para 3750 MW. Tanto Jirau quanto Santo Antônio são compostas por turbinas bulbos e são consideradas usinas a fio d'água, a primeira com 22 turbinas e a segunda com 28, juntas totalizando 50 turbinas (BORGES, 2017). Essa "tecnologia a fio d'água com turbinas bulbo representa uma melhoria, mas não é a tecnologia benigna, quase sem impacto, sugerida pelos proponentes do projeto" (FEARNSIDE, 2015a, p. 170).

Com 2.400 km de extensão, as linhas de transmissão destas usinas saem da subestação coletora de Porto Velho, com corrente contínua de alta tensão de $600 \mathrm{kV}$,

\footnotetext{
${ }^{2}$ A IIRSA surgiu no ano 2000 e foi, posteriormente, incorporada à União das Nações Sul-Americanas (UNASUL) em seu Conselho Sul-Americano de Infraestrutura e Planejamento (COSIPLAN).
} 
para a subestação em Araraquara se conectando com o SNI, e que, segundo os concessionários, serão as maiores do mundo em operação (BORGES, 2017). Desde 2013, Jirau está em operação com todas as suas turbinas em funcionamento. É importante ressaltar que "o rio Madeira é um dos maiores rios do mundo, embora seja um mero afluente do rio Amazonas. A vazão média do rio Madeira de $17.686 \mathrm{~m} 3 / \mathrm{s} \mathrm{em}$ Jirau é 24\% maior do que a do rio Yangtzé na altura da barragem de Três Gargantas, na China" (FEARNSIDE, 2015a, p. 138).

O licenciamento ambiental das duas usinas hidrelétricas esteve sob responsabilidade do Instituto Brasileiro do Meio Ambiente e dos Recursos Naturais Renováveis (IBAMA) e foi um processo cercado de controvérsias em um período que o próprio órgão ambiental e o Ministério de Meio Ambiente sofriam grande pressão para aprovação de projetos de infraestrutura (THUWOHL, 2008). Os Estudos de Impacto Ambiental e o Relatório de Impacto Ambiental (EIA/RIMA) e os estudos de viabilidade foram realizados simultaneamente para Santo Antônio e Jirau, finalizados em 2005 e aprovados pelo IBAMA em 2006 (FEARNSIDE, 2015a; SWITKES, 2008).

O processo de licenciamento ambiental das duas usinas do Complexo do Madeira são "uma ilustração da suscetibilidade do sistema à pressão política e estabelece precedentes que enfraquecem as salvaguardas para futuras barragens" (FEARNSIDE, 2015a, p. 172). A pressão política levou a substituição dos encarregados pelo processo no âmbito do IBAMA em diversos momentos do licenciamento, somadas às mudanças significativas que ocorreram como a divisão do IBAMA em dois, com a criação do Instituto Chico Mendes encarregado das Unidades de Conservação.

Fearnside (2015a, 2015b) publicou diversos artigos em que analisa o processo de construção e os impactos das hidrelétricas na Amazônia. Ele apontou, por exemplo, os impactos das barragens do Complexo do Madeira que poderiam ter servido de lições para o processo de tomada de decisões sobre o desenvolvimento hidrelétrico na Amazônia. Destaca-se: os impactos transfronteiriços de inundações na Bolívia, bem como na biodiversidade de peixes migratórios da Bolívia e do Peru; perda de ecossistemas naturais; impactos sobre os peixes e a pesca (que é uma importante fonte de subsistência e renda para a população local); impactos do mercúrio; impactos da emissão de gases de efeito estufa. Além dos impactos à jusante das barragens que incluem a erosão fluvial e os sedimentos em lagos de várzea. Entre os impactos 
sociais destaca-se o aumento do nível da água com as barragens, que gera 0 deslocamento de pessoas afetadas.

Todavia, o número de pessoas afetadas foi subdimensionado, além do que muitas pessoas foram atraídas para trabalhar na construção, e depois encontraram dificuldades para alcançar outros postos de trabalho após a finalização das barragens, além do impacto sobre a pesca e o crescimento da população de Porto Velho que causa pressão sobre os serviços públicos urbanos. Não cabe aqui detalhar cada impacto apontado por Fearnside (2015a, 2015b), pois além dele próprio outros pesquisadores e organizações da sociedade civil publicaram diversos artigos, livros e dossiê relatando estes impactos em detalhes (SANT'ANNA, 2012; CAVALCANTE, 2012; MOLINA, 2008; BORGES, 2017; HERRERA, 2017; SWITKES, 2008).

A partir disso, o que se pretende é demonstrar que apesar de todos estes estudos e impactos analisados, ainda assim os projetos foram desenvolvidos e, neste processo, diferentes estratégias foram utilizadas para sua despolitização. Exemplo disso são as tentativas de apontar os seus benefícios e sua suposta segurança técnica. A mobilização social contrária buscou a sua repolitização a partir da contestação dos dados, projetos e procedimentos.

As análises de Fearnside (2015a) demonstram como na defesa da construção das hidrelétricas de Santo Antônio e Jirau foram empregadas como estratégia de despolitização o exagero dos benefícios da produção de eletricidade e a minimização dos impactos e preocupações sociais e ambientais. A questão dos impactos dos sedimentos é um exemplo de como se produz a ignorância por meio das escolhas dos dados a serem levados em conta que beneficiam a defesa da construção dos projetos:

$\mathrm{O}$ rio Madeira tem uma das maiores cargas de sedimentos entre os rios do mundo, contribuindo com cerca da metade do total transportado para o Atlântico pelo rio Amazonas (e.g., Meade, 1994) [...]. O Estudo de Viabilidade e o EIA/RIMA calcularam uma rápida acumulação de sedimentos nos reservatórios [...]. Pouco antes da aprovação da licença prévia para Santo Antônio e Jirau, um relatório de consultoria encomendado pelo Ministério das Minas e Energia (Alam, 2007) alterou o cenário oficial completamente para um no qual não haveria nenhuma acumulação de sedimentos em todos os reservatórios (FURNAS \& CNO, 2007, p. 22). A confiabilidade desta conclusão tem sido fortemente contestada (Dunne, 2007; Molina Carpio, 2007; Tucci, 2007). A polêmica dos cenários oficiais para a acumulação de sedimentos mostra tanto o elevado grau de incerteza em que as barragens foram licenciadas e a tendência a adotar, seletivamente, interpretações favoráveis às barragens (Fearnside, 2013a) (FEARNSIDE, 2015a, p. 149). 

dados mais favoráveis à construção das barragens em resposta aos pareceres do IBAMA para a concessão das licenças:

Em 21 de março de 2007, como parte do processo de concessão da Licença Prévia, a equipe técnica do departamento de licenciamento do IBAMA apresentou um parecer de técnica de 221 páginas oposto à aprovação da Licença Prévia (Deberdt et al., 2007). [...] Muitos dos pontos levantados foram obtidos a partir da avaliação independente encomendada pelo Ministério Público de Rondônia (COBRAPE, 2006). O chefe do Departamento de Licenciamento foi imediatamente substituído, supostamente como um sinal do descontentamento do governo com a posição da equipe técnica (Faleiros, 2007). Mesmo que no seu despacho afirmou que "deixo de acolher" o parecer negativo da equipe técnica, ele pediu estudos posteriores em vez de autorizar imediatamente a concessão da Licença Prévia (Kunz Júnior, 2007) [Obs. Kunz Júnior foi removido do cargo pouco tempo depois.]. O parecer técnico feito pela equipe do Departamento de Licenciamento havia solicitado que um novo EIA/RIMA seja elaborado. A equipe depois apresentou uma série de 40 perguntas a serem respondidas pelos proponentes (Brasil, IBAMA, 2007a,b,c). Um editorial no jornal O Estado de São Paulo classificou o pessoal do IBAMA como se envolver em "molecagem" no tratamento de um projeto tão importante, fazendo perguntas "com o objetivo transparente de rejeitar o licenciamento prévio" (OESP, 2007). (FEARNSIDE, 2015a, p. 173)

Com isso em mente, Fearnside (2015a) aponta que estes casos demonstraram que os estudos de impactos ambientais, bem como as audiências públicas, não tiveram qualquer efeito significativo sobre as decisões tomadas para o licenciamento das obras. O autor enfatiza que os procedimentos e as etapas dos processos são cumpridos, mas o conteúdo pouco importa, pois tudo é feito para que os projetos se concretizem não importando as falhas no EIA/RIMA e o não cumprimento de condicionantes durante o licenciamento.

Essa desconsideração quanto ao conteúdo dos estudos publicados no EIA/RIMA é uma consequência das constantes pressões exercidas por grupos de atores específicos, que enxergam seus interesses atendidos na continuidade da construção das barragens, ainda que os impactos ambientais e sociais indicados sejam destrutivos. Dentre tais atores estão as grandes construtoras e suas associadas, como o Consórcio Construtor Odebrecht e Gutierrez (ou Consórcio Santo Antônio Civil), grupos industriais regionais, empresas privadas de fornecimento de energia, como a CEMIG e a Light, a Eletrobrás e a Eletronorte, e os grandes bancos privados e públicos, como o Santander e o BNDES (Banco Nacional de Desenvolvimento Econômico e Social), que realizaram investimentos massivos para que essas grandes obras fossem erigidas (BORGES, 2017; INESC, 2020). 
Esses atores também estiveram presentes no processo de construção da usina de Belo Monte no rio Xingu, no município de Altamira (Pará), que com um reservatório de $668 \mathrm{~km}^{2}$ foi proclamada como a segunda maior do país e a terceira do mundo. Os debates sobre a construção desta usina tiveram início na virada da década de 1960 para a de 1970, estimulados pela demanda dos projetos de produção de alumínio na região. A defesa da construção, efetivamente, aconteceu a partir do lançamento do $u$ Plano 2010, que posicionou o rio Xingu como de extrema importância para o setor energético brasileiro. Este Plano incluía Kararaô (Belo Monte) para construção até 2000 e Babaquara (Altamira) para construção até 2005 (FEARNSIDE, 2015a; PEREIRA, 2013).

Para Choueri (2019) os atores que promoveram o projeto juntamente com líderes políticos nacionais e locais formam o grupo de pressão para a construção de hidrelétricas como Belo Monte, que atuaram buscando conseguir legitimação social para o projeto a partir de sete estratégias principais:

(i) discurso de segurança energética e apropriação simbólica do conceito de sustentabilidade; (ii) expectativa de geração de emprego e renda; (iii) cooptação de lideranças; (iv) papel da mídia; (v) procedimento de licenciamento ambiental federal; (vi) papel do judiciário e monopólio legítimo da violência; e, (vii) envolvimento do legislativo. Assim, Belo Monte implantouse como resultado da vitória dos grupos de pressão em realizar um grande pacto nacional, coordenado nos três Poderes, (Executivo, Legislativo e Judiciário) com o apoio da mídia, superando a resistência das organizações dos indígenas, dos ribeirinhos e pescadores, da prelazia e dos ambientalistas (CHOUERI, 2019, pp. 157-158).

A UHE de Belo Monte já se encontra em operação desde 2019, com a Licença de Operação concedida pelo IBAMA em 24 de novembro de 2015 (INESC, 2020). Ela possui a capacidade de 11.233 MW e como energia firme média de 4.571 MW e é operada pela Consórcio Norte Energia S.A. No entanto, dados aponta que:

a usina de Belo Monte foi superdimensionada. A capacidade de 11,2 mil MW só estará disponível durante três meses do ano. Nos meses de setembro e outubro, quando o rio Xingu fica naturalmente mais seco, a capacidade instalada aproveitável da hidrelétrica não será maior do que $1.172 \mathrm{MW}$. Ou seja, $90 \%$ da usina ficará parada. Esta esdrúxula situação, sob o ponto de vista técnico, foi determinada pelas tentativas de reduzir as consequências socioambientais da obra, com a operação a fio d'água, isto é, sem um grande reservatório capaz de regularizar a vazão. Este fator de capacidade, de 39\% ao longo do ano, é muito baixo, em relação à média das hidrelétricas brasileiras, de 55\% (BERMANN C. M., 2012, p. 12).

O projeto para Belo Monte teve de ser alterado uma série de vezes, com o início das construções ocorrendo somente em 2011. Um dos fatores que explicam isso é a 

civil, principalmente a partir dos protestos de povos indígenas, estava preocupado com os efeitos socioambientais negativos na bacia do Xingu. Ainda, essas representações defendiam também um processo decisório sobre a construção de barragens mais participativo do que se configurava naquele contexto.

Em fevereiro de 1989, por exemplo, os Kaiapós foram fundamentais na organização do Encontro dos Povos Indígenas do Xingu em Altamira para protestar contra as represas planejadas na Amazônia (FEARNSIDE, 2015a; PEREIRA, 2013). É interessante ressaltar que neste encontro o então diretor da Eletronorte presente "anunciou que, por significar uma agressão cultural aos índios, a usina Kararaô - nome que é um grito de guerra Kayapó - receberia outro nome e não seriam mais adotados termos indígenas em usinas hidrelétricas" (FLEURY e ALMEIDA, 2013, p. 143).

Um dos grandes problemas apontados por especialistas e grupos da população local é o fato de que a usina de Belo Monte como foi construída gerou um extenso Trecho de Vazão Reduzida (TVR), devido ao desvio do rio para outro local para a geração de energia hidrelétrica a partir do canal de derivação da vazão até o canal de restituição da vazão:

Para o caso de Belo Monte, o TVR possui extensão de $130 \mathrm{~km}$ ao longo do canal principal de escoamento no período de estiagem ou $100 \mathrm{~km}$ pela linha média na seção transversal, no trecho conhecido pela volta grande do Xingu (VGX). Parte da vazão que naturalmente percorreria a VGX agora é desviada para o reservatório de canais, e uma vazão remanescente continua fluindo para a VGX. A VGX possui como característica principal ser um ambiente de pedrais, único na bacia, propício, sobretudo ao hábitat de espécies da ictiofauna endêmicas (CHOUERI, 2019, p. 30).

Em publicação de novembro de 2019 para o jornal El País, Eliane Brum (2019) mostra como a seca severa no rio Xingu compromete a segurança da hidrelétrica de Belo Monte, e tem afetado a qualidade da água e a pesca na VGX: Estudos científicos mostram que, no futuro, a crise climática tornará as secas
ainda mais severas. "Um destes estudos, de 2016, projeta a redução de cerca
de $50 \%$ na vazão do rio Xingu no período de 2070 a 2099 ", afirma o geólogo
André Oliveira Sawakuchi, do Departamento de Geologia Sedimentar e
Ambiental do Instituto de Geociências da Universidade de São Paulo, que
também analisou o documento a pedido do EL PAís. "Projeçães específicas
para Belo Monte, considerando um cenário de mudança climática, apontam
redução de aproximadamente $30 \%$ (em relação à média histórica 1971-2014)
da vazão afluente no Reservatório Pimental, para o período 2020-2050.
Portanto, condições de vazão afluente reduzida, tal como em outubro de
2019 , podem ser mais frequentes e/ou intensas durante a fase de operação
da usina. Isto implica intensificação do conflito." Ao mesmo tempo, o
desmatamento acelerado, que explodiu na região, em grande parte
provocado pela construção de Belo Monte, também altera o comportamento 
do rio. A derrubada da mata no Alto Xingu, região de expansão da soja, afeta ainda mais.

Fearnside (2015a) aponta que as autoridades do setor de energia elétrica presumiam um crescimento contínuo da economia brasileira e da capacidade de pagar por barragens, e que o processo de construção seria desimpedido de exigências de licenciamento ambiental e contaria com a ampla disponibilidade de empréstimos dos bancos multilaterais de desenvolvimento sem a necessidade de apresentar os estudos e relatórios que atestavam a ausência de danos deletérios ao meio ambiente. Sendo assim, o paradigma que se construiu a partir da Usina Hidrelétrica de Belo Monte foi "a emergência de uma autocracia energética, com a negação da democracia no nosso país e no continente latino-americano" (BERMANN, 2012, p. 22).

A despolitização discursiva que nega e exclui outras interpretações e escolhas, também se utiliza de narrativas simplificadas que propõem soluções simplistas para problemas complexos como é a política energética de um país. Neste sentido, "o uso a ser feito da energia não tem sido objeto de debate aberto no Brasil" (FEARNSIDE, 2015a p. 175), pois existem processos de despolitização desta temática que buscam esvaziar este debate. E a narrativa simplista tem se baseado na interpretação de que a única solução possível para política energética no Brasil é o incremento da oferta de energia para atender aos cenários de demanda crescente. No entanto, o aumento da oferta de energia é para qual uso? Seria possível diminuir ou gerir a demanda por energia? Quais usos devem ser priorizados? São questionamentos que demonstram as possibilidades de contestação.

\section{O Brasil e a mobilização social contra as hidrelétricas de Santo Antônio, Jirau e Belo Monte}

$\mathrm{Na}$ época da construção das hidrelétricas de Santo Antônio e Jirau na bacia do rio Madeira e de Belo Monte na bacia do rio Xingu, emergiram diversas mobilizações sociais contrárias a construção destes projetos. Mobilizações que formaram redes transnacionais e que engajaram diferentes grupos da sociedade brasileira e internacionais, como povos indígenas, ribeirinhos, cientistas, ONGs, ambientalistas, entre outros. Nota-se que muito da confrontação que se deu entre os grupos a favor 
e contrários aos projetos mobilizaram conhecimentos científicos ${ }^{3}$ para contestar as afirmações técnicas apresentadas pelo grupo favorável (em geral composto por funcionários do governo brasileiro e representantes de empresas envolvidas nos consórcios).

Nesse contexto, o próprio conhecimento científico foi utilizado para contestação de dados de impactos ambientais, como, por exemplo, as informações subdimensionadas sobre os reservatórios e as áreas alagadas, bem como sobre as populações afetadas e deslocadas. No entanto, a confrontação entre os grupos a favor e contrários aos projetos das hidrelétricas configuram-se também em contestações de conhecimentos, uma vez que são mobilizados conhecimentos e valores distintos como aqueles dos povos indígenas em defesa de seus territórios e culturas.

Essa reação da sociedade civil se dá pela amplitude dos impactos negativos da construção de hidrelétricas na bacia do rio Amazonas. Além de deslocar comunidades indígenas, grupos ribeirinhos e outras populações locais, esses projetos são capazes de aumentar o nível de desmatamento por conta da construção de estradas de acesso e aumento da população e atividades exploratórias, contaminar as águas e, consequentemente, afetar os peixes que são consumidos por esses grupos, agravar a ocorrência de doenças como a malária e intensificar o índice de emissão de gases de efeito estufa (FEARNSIDE, 2015a).

Desde os anos 1980 que diversos grupos da sociedade civil se mobilizaram contra o projeto de Belo Monte. Nos anos 2000 a mobilização se intensificou com a retomada dos estudos de viabilidade do projeto. Essa mobilização deu origem ao Movimento Xingu Vivo para Sempre (MXVPS), a diversas campanhas de ONGs, documentários, campanhas na mídia com artistas, documentos técnicos e científicos que contestavam o EIA/RIMA, o licenciamento ambiental ${ }^{4}$, e o projeto em si. No dia 12 abril de 2010 ocorreu uma marcha composta por diversos grupos em Brasília para protestar contra à construção de Belo Monte. O MXVPA foi uma das primeiras organizações sociais opositoras ao projeto de Belo Monte atuando desde 2008 na região de influência do projeto. O movimento é formado por diversas organizações,

\footnotetext{
${ }^{3}$ Como por exemplo o caso do Painel de Especialistas no caso de Belo Monte, composto por 40 especialistas de diversas áreas de conhecimento científico (HERNANDEZ, 2017). E o relatório da Sociedade Brasileira para o Progresso da Ciência "A expulsão de ribeirinhos em Belo Monte: relatório da SBPC" (MAGALHÃES e CUNHA, 2017).

${ }^{4}$ FLEURY e ALMEIDA (2013) fizeram um mapeamento dos principais atores a favor e contrários ao projeto de Belo Monte, e do conflito em si.
} 
comunidades tradicionais, ribeirinhos e pescadores, trabalhadores, entre outros, com apoio de organizações locais, regionais, nacionais e internacionais (FLEURY e ALMEIDA, 2013).

É importante ressaltar que os grupos de pessoas afetadas pelas barragens também já se organizavam em torno de seus direitos e interesses derivados de obras anteriores de hidrelétricas pelo Brasil, o que resultou na criação do Movimento Atingidos por Barragens (MAB) na década de 1990. O MAB tem atuado para a repolitização dos projetos de hidrelétricas e da própria política energética do país (HERNANDEZ, 2017).

A mobilização das pessoas atingidas por barragens se dá como contraposição aos riscos desiguais produzidos pela construção das usinas hidrelétricas. Um exemplo é o caso da construção de Jirau. A concessionária construiu uma cidade artificial, a Nova Mutum, devido ao alagamento do distrito de Mutum-Paraná que foi gradualmente abandonado. Em 2010 as pessoas começaram a se deslocar para a nova cidade. No entanto, muitos acabaram deixando Nova Mutum e se instalando novamente em Jirau às margens da BR-364, "devido à inadequação do remanejamento às necessidades materiais e simbólicas da comunidade de MutumParaná" (STOLERMAN et al., 2017, p. 244).

Esse acontecimento se enquadra na discussão proposta por Martínez-Alier (2012) sobre a incomensurabilidade de valores. Nesse sentido, alguns atores apontam que "as cidades ribeirinhas, dessa forma, têm fortes enraizamentos, fortes ligações socioeconômicas e culturais com a escala geográfica local e regional; enraizamentos estes que traduzem estreita relação com o rio" (STOLERMAN et al., 2017, p. 246247). Trata-se, portanto, de um processo de:

reterritorialização em oposição à uma desterritorialização, em virtude de um reassentamento inadequado, o que se pode configurar como uma 'estratégia de luta pela apropriação material e simbólica do espaço' (ACSERALD e SILVA, 2011, p. 70) (STOLERMAN et al., 2017, p. 250).

Neste caso, mas também no de Belo Monte existe uma desconsideração sobre os impactos negativos para a vida das populações que vão além daqueles da "área diretamente afetada". A CMB entende que o deslocamento acomete também os modos de vida dos chamados "atingidos" e não somente na área da construção das usinas e linhas de transmissão: 
[...] o alagamento de terras e a alteração do ecossistema dos rios - seja a jusante ou a montante da barragem - também afetam os recursos disponíveis nessas áreas - bem como as atividades produtivas. No caso de comunidades dependentes da terra e de recursos naturais, isso resulta frequentemente na perda de acesso aos meios tradicionais de vida, incluindo a produção agrícola, a pesca, a pecuária, o extrativismo vegetal, para citar alguns exemplos. Isso provoca não apenas rupturas na economia local, como efetivamente o deslocamento das populações - em um sentido mais amplo do acesso a recursos naturais e ambientais essenciais ao seu modo de vida (CMD, 2000, p. 102-103 apud HERNANDEZ, 2012).

$\mathrm{Na}$ contramão das mobilizações sociais em torno da construção das hidrelétricas, é notável o discurso de diversos presidentes e ministros, portanto, representantes do poder Executivo, classificando a manutenção das políticas ambientais, de proteção aos povos indígenas e garantias da sua participação no processo decisório como obstáculos ao desenvolvimento regional e nacional. Inclusive, tais atores da burocracia governamental buscaram modificar a legislação dessas políticas como forma de "desobstruir" projetos de desenvolvimento e de interesse nacional. Podemos citar por exemplo, as mudanças no Código Florestal brasileiro, as mudanças no Licenciamento Ambiental e até mesmo alteração dos limites de Terras Indígenas (ACSELRAD, et al., 2012; HERNANDEZ, 2012).

Além da mobilização social, estas grandes hidrelétricas na Amazônia brasileira têm levado à judicialização desses empreendimentos devido aos conflitos socioambientais que se agravam com a não adequação do licenciamento ambiental aos seus propósitos. Scabin, Pedroso Júnior e Cruz (2014) fizeram um estudo com base na análise de quarenta Ações Civis Públicas (ACP) relacionadas às usinas de Belo Monte, Jirau e Santo Antônio até o período de abril de 2014 para compreender esse processo de judicialização. Os autores afirmam que grande parte das ACP analisadas se referem aos impactos das usinas nas populações locais, questionando principalmente, a falta de consulta prévia às populações impactadas e o não cumprimento de condicionantes presentes no licenciamento ambiental, incluindo impactos subdimensionados apresentados nos EIA/RIMAs. Nesse sentido eles apontam que:

pode-se observar que o Judiciário tem funcionado como única instância de solução de controvérsias, ante a ausência e/ou inefetividade de canais que possam assim funcionar dentro de um processo de licenciamento ambiental. Apesar desta constância, o que se observa são padrões distintos nos casos aqui considerados. Nas ações referentes à Belo Monte, o Judiciário tem intervindo por meio de liminar nos casos em que se demonstra violação aos direitos das populações impactadas ou às regras do próprio licenciamento. Porém essas ações são revogadas em segunda instância, quando o 
Judiciário se abstém de decidir, sob o fundamento de se tratar de "grave lesão à ordem, à saúde e à economia públicas", sobre o que cabe decidir o Executivo. Já nas ações de Santo Antônio e Jirau, o Judiciário tem indeferido as ações relacionadas ao licenciamento ambiental de ambas as usinas, com exceção de duas ações que contestam a violação de direitos à moradia e dignidade da pessoa humana das populações impactadas (SCABIN, et al., 2014, p. 146)

Os autores chamam esse processo de recolhimento do Judiciário em que a utilização da Suspensão de Segurança impede que as ações tenham um efeito prático sobre os pedidos de apreciação das violações alegadas. Dessa forma, a judicialização nesses casos, ou seja, recorrer ao Judiciário, tanto não tem ajudado muito as populações locais, como também tem agravado a assimetria de poder a favor tanto das concessionárias como dos órgãos federais como o IBAMA e impactado o próprio procedimento do licenciamento ambiental que não é cumprido em suas normas e não consegue prevenir adequadamente os danos ambientais (SCABIN, et al., 2014).

Outro aspecto citado pelos autores é que as análises sobre as ACP têm sido direcionadas pela perspectiva de uma "iminente crise energética - que estaria sendo prevenida através de um plano que não pode ter o seu conjunto 'prejudicado' por esses casos isolados". Todavia, as hidrelétricas são fruto de programas, planos e políticas públicas em que as instituições políticas têm liberdade para agir, mas para agir dentro da lei e não fora dela e, portanto, podem ser objeto de análise de um tribunal. O período do trâmite das ACP extremamente longo não teria problema se as obras não fossem continuadas e as liminares suspensas. $O$ que apenas reforça a assimetria de poderes constatada entre as populações locais e as concessionárias, bem como a "inabilidade do Judiciário em resolver conflitos não solucionados durante os procedimentos previstos pelo licenciamento ambiental" (SCABIN, PEDROSO JÚNIOR, \& CRUZ, 2014, p. 147-148). A somatória desses elementos "sugere, ainda, a necessidade de uma abordagem baseada em direitos durante estágios preliminares do processo de tomada de decisões, concepção de projetos e licenciamento, de forma a se evitar a judicialização" (SCABIN, PEDROSO JÚNIOR, \& CRUZ, 2014, p. 147148).

\section{Considerações Finais}


O presente artigo buscou contribuir para a análise da despolitização da temática em torno das grandes hidrelétricas na Bacia Amazônica brasileira. A análise se baseou nas estratégias de despolitização e de produção da ignorância, que estão relacionadas à supressão de dados e informações sobre os riscos socioambientais das usinas, bem como a distribuição desigual dos mesmos, como foi apresentado nos casos de Santo Antônio, Jirau e Belo Monte.

Podemos concluir que entre as estratégias de despolitização foram utilizados discursos que buscavam tratar o tema das hidrelétricas de forma técnica-científica visando deslegitimar o discurso dos opositores como obstáculos ao progresso e desenvolvimento, ou até mesmo contrários aos interesses nacionais. Outra estratégia foi a produção da ignorância com a alteração de dados utilizados nos processos de licenciamento, além da constante alteração das pessoas encarregadas dos processos, e ignorando impactos às populações locais mediante, por exemplo, o subdimensionamento ou supressão de impactos negativos das barragens, ou restringindo o entendimento de populações afetadas. Ocorreu também a judicialização dos conflitos com a delegação da temática para os órgãos e estruturas judiciais. A promoção de um discurso de necessidade de aumentar a oferta energética como a única saída possível, foi uma estratégia utilizada para legitimar a construção das hidrelétricas ao promover a temática a partir de uma única interpretação, negando a existência de uma escolha política e ignorando outras interpretações e escolhas possíveis.

Nota-se, portanto, que o avanço da fronteira hidrelétrica na Amazônia brasileira se configura a partir da disputa pelo acesso a estes territórios e seus recursos naturais. É o processo global de acumulação que avança sobre os rios da maior bacia hidrográfica do mundo. Por outro lado, a globalização também se configura pela criação de redes transnacionais de movimentos e mobilização social em conflitos socioambientais até então tido como locais. Futuros desdobramentos desse estudo poderiam levar a análise de como o discurso de segurança energética, que tem justificado a expansão da hidroeletricidade, tem levado a uma securitização da temática e sua relação com a despolitização, o esvaziamento e simplificação do debate sobre as energias renováveis e as mudanças climáticas.

\section{Referências}


ACSELRAD, H.; WAGNER, A. A.; BERMANN, C.; BRANDÃO, C. A.; CARNEIRO, E.; LEROY, J. P.; LISBOA, M.; MELLO, C.; MILANEZ, B.; NOVOA, L.; O'DWYER, E.; RIGOTTO, R.; SANT'ANA JÚNIOR, H.; VAINER, C.; ZHOURI, A. Desigualdade ambiental e acumulação por espoliação: o que está em jogo na questão ambiental. ecadernos CES , v. 17, sem página, 2012. Doi:10.4000/eces.1138.

AHLERS, R.; BUDDS, J.; JOSHI, D.; MERME, V., e ZWARTEVEEN, M. Framing hydropower as green energy: assessing drivers, risks and tensions in the Eastern Himalayas. Earth System Dynamics, V. 6, p. 195-204, 2015.

ANA. Agência Nacional de Águas. Sala de Situação Madeira Saiba Mais. Disponível em: <https://www.ana.gov.br/sala-de-situacao/rio-madeira/saiba-mais >. Acessado em 21 de maio de 2020.

ATKINS, E. Disputing the 'National Interest': The Depoliticization and Repoliticization of the Belo Monte Dam, Brazil. Water, v. 11, p. 1-21, 2019. Doi:10.3390/w11010103.

BANDEIRA, F. M. P. O Processo de Privatização do Setor Elétrico Nacional. Brasília: Consultoria Legislativa da Câmara dos Deputados, 2005

BECK, U. Sociedade de risco: ruma a uma outra modernidade. São Paulo: 34, 2011.

BECKER, B. K. Amazônia: Geopolítica na virada do III milênio. Rio de Janeiro: Garamond, 2007.

BERMANN, C. O projeto da Usina Hidrelétrica Belo Monte: a autocracia energética como paradigma. Novos Cadernos NAEA, v. 15, p. 5-23, 2012.

BERMANN, C., WITTMANN, D., MORAL HERNANDEZ, F. d., e RODRIGUES, L. A. Usinas hidrelétricas na Amazônica: o futuro sob as águas. Anais. Cenários e desafios para a governança socioambiental. Brasília: INESC, 2010. Disponível em: < http://www.iee.usp.br/sites/default/files/biblioteca/producao/2010/Trabalhos/bermannusinas.p df> Acessado em 4 de abril de 2020.

BOELENS, R., DAMONTE, G., SEEMANN, M., DUARTE, B., \& YACOUB, C. Despojo del agua en Latinoamerica: una introducción a la ecologia política del agua en los agronegocios, la minería y las hidroeléctricas. In: C. YACOUB, B. DUARTE, e BOELENS, R. Agua y Ecología Política: el extractivismo en la agroexportación, la minería y las hidroeléctricas. Quito: Abya-Yala, 2015, p. 11-29.

BOELENS, R., SHAH, E., \& BRUINS, B. Contested Knowledges: Large Dams and Mega-Hydraulic Development. Water, v. 11, p. 1-27, 2019. Doi:10.3390/w11030416.

BORGES, L. R. Efeitos territoriais de hidrelétricas na Amazônia: o caso do complexo do Madeira e suas imediações. In: Herrera, J. A. \& Calvacante, M. M. Hidrelétricas na Amazônia: implicações nas áreas de influência das Usinas nos rios Xingu (pará) e MAdeira (Rondônia). Belém: GAPTA/UFPA, 2017, p. 193-226. 
BOSSHARD, P. The Dam Industry, the World Commission on Dams and the HSAF Process. Water Alternatives, v.3, p. 58-70, 2010.

BRASIL. Ministério de Minas e Energia. Matriz Energética Nacional 2030. Brasília: MME, EPE, 2007. Disponível em:< http://www.mme.gov.br/documents/36208/461919/Matriz+Energ\%C3\%A9tica+Nacional+20 30.pdf/cf7e0f4c-8067-6856-150e-b53d9bbd81b2?version=1.0> Acessado em 14 de abril de 2020.

BRASIL. Ministério de Minas e Energia. Plano Decenal de Expansão de Energia 2021. Brasília, DF: MME: EPE, 2012. Disponível em: http://www.epe.gov.br/sitespt/publicacoes-dados-abertos/publicacoes/PublicacoesArquivos/publicacao-

50/topico-87/Relat\%C3\%B3rio\%20Final\%20do\%20PDE\%202021.pdf. Acessado em: 24 de fev. 2020.

BRASIL, COMITÊ INTERMINISTERIAL SOBRE MUDANÇA DO CLIMA (CIMC). Plano Nacional sobre Mudança do Clima - PNMC. Decreto n 6.263, de 21 de novembro de 2007. Brasília: CIMC, 2008.

CASTELLS, M. Ruptura: a crise da democracia liberal. (J. A. Melo, Trad.) Rio de Janeiro: Zahar, 2018.

CAVALCANTE, M. M. Hidrelétricas no rio Madeira-RO: tensões sobre o uso do território e dos recursos naturais na Amazônia. CONFINS, v. 15, p. 1-15, 2012.

CDM, COMISSÃO MUNDIAL DE BARRAGENS. Dams and Development: a new framework for decision-making - The report of the World Comission on Dams. Londres: Earthscan Publications, 2000.

CHOUERI, R. B. Conflito, licença ambiental e energia na Amazônia: análise dos conflitos socioambientais produzidos pela Usina hidrelétrica de Belo Monte (PA) relacionados à biodiversidade aquática e pesca. Tese de doutorado em Desenvolvimento Sustentável, Universidade de Brasília, 2019.

FEARNSIDE, P. M. Hidrelétricas da Amazônia: impactos sociais e ambientais na tomada de decisão de grandes obras (Vol. 1). Manaus: INPA, 2015a.

FEARNSIDE, P. M. Hidrelétricas na Amazônia: impactos ambientais e sociais na tomada de decisões sobre grandes obras (Vol. 2). Manaus: INPA, 2015b.

FLEURY, L. C. e ALMEIDA, J. A construção da usina hidrelétrica de Belo Monte: conflito ambiental e o dilema do desenvolvimento. Ambiente \& Sociedade, n. 4, p. 141158, 2013.

FOUCAULT, M. Microfísica do poder. (O. e. Machado, Trad.) Rio de Janeiro: Edições Graal, 1979. 
GOLDMAN, M. How "Water for All!" policy became hegemonic: The power of the World Bank and its transnational policy networks. Geoforum, v. 38, p. 786-800, 2007. Doi:10.1016/j.geoforum.2005.10.008

HAY, C. Why we hate politics? Cambridge (MA): Polity Press, 2007.

HERNANDEZ, F. del M. Hidrelétricas na Amazônia: renovabilidade e não renovabilidade da política energética. Se é desejável a renovabilidade das formas de conversão de energia, porque não é desejável renovar a política energética. Boletim Museu Baraense Emílio Goeldi, v. 7, n. 3, p. 791-811, 2012.

HERNANDEZ, F. M. A luta por reconhecimento como processo educativo: paisagem, educação ambiental, educação social. Saber \& Educar, v. 22, p. 72-81, 2017.

HERRERA, J. A. (ed.). Hidrelétricas na Amazônia: implicações territoriais nas áreas de influência das usinas nos rios Xingu (Pará) e Madeira (Rondônia). Belém (PA): GAPTA/UFPA, 2017.

HUBER, A. Hydropower in the Himalayan Hazardscape: Strategic Ignorance and the Production of Unequal Risk. Water,v. 11, n. 414, p. 1-23, 2019a. Doi:10.3390/w11030414

HUBER, A. Governing 21st century dams: hydropower, knowledge politics and popular struggles in India's Eastern Himalayan borderland. Tese de doutorado em Ciência e Tecnologia Ambiental, Universidade Autônoma de Barcelona, $2019 \mathrm{~b}$.

HUBER, A., Gorostiza, S., Kotsila, P., Beltrán, M. J., \& Armiero, M. Beyond "Socially Constructed" Disasters: Re-politicizing the Debate on Large Dams through a Political Ecology of Risk. Capitalism Nature Socialism, v. 28, n. 3 p. 48-68, 2016. Doi: 10.1080/10455752.2016.1225222

IEA. Tracking power 2019. Disponível em: <https://www.iea.org/fuels-andtechnologies/hydropower>. Acessado em 05 de abril de 2020.

INESC. Belo Monte. Disponível em: <http://amazonia.inesc.org.br/banco-de-dadoshidreletricas-na-amazonia/belo-monte/>. Acessado em: 04 de abril de 2020.

JENKINS, L. (2011). The Difference Genealogy Makes: Strategies for Politicisation or How to Extend Capacities for Autonomy. Political Studies, v. 59, p. 156-174, 2011. Doi: 10.1111/j.1467-9248.2010.00844.x.

LAYRARGUES, P. P. Quando os ecologistas incomodam: a desregulação ambiental pública no Brasil sob o signo do Anti-ecologismo. RP3 Revista de Pesquisa em Políticas Públicas, p. 1-30, 2018. DOI: https://doi.org/10.18829/rp3.v0i12.26952

MAGALHÃES, S. B. e CUNHA, M. C. (orgs.). A expulsão de ribeirinhos em Belo Monte: relatório da SBPC. São Paulo: SBPC, 2017 
MARTINEZ-ALIER, Joan. Ecologismo dos pobres: conflitos ambientais e linguagens de valoração. São Paulo: Contexto, 2007.

MARTINS, R. C., e LIMA, M. J. Capital cultural na gestão ambiental por bacias hidrográficas. In: Castro, J. E., Cunha, L. H., Fernandes, M. \& Souza, C. M. Tensões entre justiça ambiental e justiça social na América Latina: o caso da gestão da água. Campina Grande (PB): UEPB, 2017, p. 131-149.

MOHAMUD, M. e. (2016). Re-Engineering the State, Awakening the Nation: Dams, Islamist Modernity and Nationalist Politics in Sudan. Water Alternatives, v. 9, p. 182202, 2016.

MOLINA, J. C. (2008). Hidrologia e Sedimentos. In: SWITKES, G. (ed.). Águas Turvas: alertas sobre as consequências de barrar o maior afluente do Amazonas. São Paulo (SP): International Rivers, 2008, p. 50-93.

MOTTA, Célia Maria da. A política de reformas do Estado brasileiro, na década de 1990: uma inserção neoliberal? Dissertação de Mestrado em Ciências Sociais, PUCSP, 2001.

OBSERVATÓRIO DO CLIMA. The worst is yet to come: A year of environmental havoc under Brazil's far-right President Jair Bolsonaro. Madrid: Observatório do Clima, 2019. Disponível em: <http://www.observatoriodoclima.eco.br/wpcontent/uploads/2020/01/Relato\%CC\%81rio-COP25-Ajustes-v3.pdf>. Acessado em 22 de maio de 2020.

PEREIRA, A. K. Desenvolvimentismo, conflito e conciliação de interesses na política de construção de hidrelétricas na Amazônia Brasileira. Rio de Janeiro: IPEA, 2013.

SANT'ANNA, F. M. Análise das relações entre Bolívia e Brasil sobre os recursos hídricos compartilhados na Bacia Amazônica: das relações internacionais às regiões de fronteira . Anais do VI Encontro Nacional da ANPPAS. Belém (PA): ANPPAS, 2012.

SANT'ANNA, F. M. Governança multiescalar dos recursos hídricos transfronteiriços na Amazônia. São Paulo: UNESP, 2017.

SCABIN, F. S., PEDROSO JÚNIOR, N. N., \& CRUZ, J. C. Judicialização de grandes empreendimentos no Brasil: uma visão sobre os impactos da instalação de usinas hidrelétricas em populações locais na Amazônia. Revista de Pós-graduação em Ciências Sociais, v. 11, p. 129-150, 2014.

STOLERMANN, P.; SANTOS, S. C.; FLORIANI, N.; SILVA, A. A. Reflexões sobre a Usina hidrelétrica de Jirau, no rio Madeira e os processos de territorialização em Rondônia. In: HERRERA, J. A. (ed.). Hidrelétricas na Amazônia: implicações territoriais nas áreas de influência das usinas nos rios Xingu (Pará) e Madeira (Rondônia). Belém (PA): GAPTA/UFPA, 2017, p. 227-244.

SWITKES, G. Águas Turvas: alertas sobre as consequências de barrar o maior afluente do Amazonas. São Paulo: International Rivers, 2008. Disponível em: 
http://www. internationalrivers.org/resources/muddy-waters-impacts-of- damming-theamazon-s-principal-tributary-3967. Acessado em 03 abril 2012.

SWYNGEDOUW, E. The Antinomies of the Postpolitical City: In Search of a Democratic Politics of Environmental Production. International Journal of Urban and Regional Research, v. 33, p. 601-620, 2009. DOI:10.1111/j.1468-2427.2009.00859.x.

SWYNGEDOUW, E. Liquid Power: Contested Hydro-Modernities in Twentieth-Century Spain. Cambridge: MIT Press, 2015.

THUWOHL, M. Marina Silva pede demissão do Ministério de Meio Ambiente. Carta Maior. 2008. Disponível em: <https://www.cartamaior.com.br/?/Editoria/MeioAmbiente/Marina-Silva-pede-demissao-do-Ministerio-do-Meio-Ambiente/3/14190>.

Acessado em: 18 de maio de 2020.

VALÊNCIO, Norma. Considerações sociológicas acerca de desastres relacionados a barragens e a atual desproteção civil de comunidades ribeirinhas conviventes com o megaempreendimento hidrelétrico de Belo Monte. In: MAGALHÃES, S. B. e CUNHA, M. C. (orgs.). A expulsão de ribeirinhos em Belo Monte: relatório da SBPC. São Paulo: SBPC, 2017, p. 167-202.

WOOD, M., \& FLINDERS, M. Rethinking depoliticisation: beyond the governmental. $\begin{array}{llllll}\text { Policy \& Politics, } & \text { v. 42, } & \text { p. }\end{array}$ Doi:http://dx.doi.org/10.1332/030557312X655909.

ZARFL, C., LUMSDON, A. E., BERLEKAMP, J., TYDECKS, L., \& TOCKNER, K. A global boom in hydropower dam construction. Aquatic Sciences, v. 77, p. 161-170, 2015. Doi:10.1007/s00027-014-0377-0. 